\title{
Prevalence and outcome of asymptomatic bacteriuria in early pregnancy
}

\section{Sreekumary Radha, Bindu Nambisan*, Nisha Kizhekkepurakkal Prabhakaran, Shahida Jamal}

Department of Obstetrics and Gynecology, Medical College, Trivandrum, Kerala, India

Received: 01 November 2016

Accepted: 29 November 2016

\section{*Correspondence:}

Dr. Bindu Nambisan,

E-mail: bindu.nambisan1971@gmail.com

Copyright: (c) the author(s), publisher and licensee Medip Academy. This is an open-access article distributed under the terms of the Creative Commons Attribution Non-Commercial License, which permits unrestricted non-commercial use, distribution, and reproduction in any medium, provided the original work is properly cited.

\section{ABSTRACT}

Background: Bacteriuria is a major risk factor for developing symptomatic urinary tract infection which is associated with significant maternal and fetal risks. Various studies have put a prevalence of asymptomatic bacteriuria between 2-10\% in pregnancy. Maternal and fetal complications like gestational hypertension, anaemia, premature delivery, IUGR, and low birth weight are commonly associated with pyelonephritis which occurs as a result of undiagnosed or inadequately treated infections of the urinary tract. The primary objective was to find out the prevalence of asymptomatic bacteriuria in pregnancies less than 28 weeks gestation in our hospital and to study the various adverse pregnancy outcomes in the study group.

Methods: This was a cross sectional study done over a period of 12 months at this tertiary care centre in Government sector in Trivandrum, Kerala. A sample size was calculated statistically and 400 women with gestational age less than 28 weeks attending the outpatient department were included in this study. A structured proforma, urine microscopy and urine culture and sensitivity were the study tools.

Results: Prevalence of asymptomatic bacteriuria in our study population was $8.25 \%$. Commonest pathogen isolated was E.coli in $57.14 \%$ cases. Maternal morbidity was higher in women with asymptomatic bacteriuria (24.2\%) than those without (12.5\%). Fetal morbidity in women with asymptomatic bacteriuria was $24 \%$ whereas it was $12.5 \%$ in those without it. Preterm labour, preeclampsia and prematurity were the common morbidities noted.

Conclusions: Since pregnant women with asymptomatic bacteriuria were at an increased risk of adverse maternal and fetal outcome, routine screening for asymptomatic bacteriuria preferably in the first trimester is highly recommended.

Keywords: Asymptomatic bacteriuria, Pyelonephritis, Urine microscopy, Urine culture

\section{INTRODUCTION}

Urinary tract infections are the most common bacterial infections during pregnancy. The incidence of UTI varies, and one of the major risk factors in developing UTI is asymptomatic bacteriuria. Urinary tract is second only to respiratory tract in acquiring microbial infection, especially in females. $90 \%$ of pregnant women develop urethral dilatation which starts at about $6^{\text {th }}$ week and peaks at about 22-24 weeks and remains so till delivery. Increased bladder volume and decreased bladder \& urethral tone contribute to increased urinary stasis and ureterovesical reflux. This accounts for $70 \%$ of asymptomatic UTI among unscreened pregnant women. Different determinants of virulence such as presence of adhesions, stasis produced by the gravid uterus etc play a role in the causation of UTI. ${ }^{1}$

The term asymptomatic bacteriuria is used when a bacterial count of the same species $>10^{5} / \mathrm{ml}$ in a midstream clean catch urine on two occasions is detected without symptoms of UTI. Delzell JE et $\mathrm{al}^{2}$ defined asymptomatic bacteriuria as persistent, actively multiplying bacteria of more than or equal to 100,000 
colony forming unit per $\mathrm{ml}$ of urine without any symptoms of urinary tract infection, which include lower abdominal pain, burning micturition, fever, dysuria, frequency, urgency, supra pubic discomfort, offensive smelling urine, strangury, urge incontinence and nocturia. The apparent reduction in immunity of pregnant women appears to encourage the growth of both commensal and non-commensal microorganisms. The female urethra is relatively short and is anatomically proximal to vagina which is colonised with organisms from GIT. Bacteria originate from the large bowel and colonize the urinary tract transperineally. The most common organism colonised is E coli. Others include Proteus, Klebsiella, coagulase negative staphylococci and pseudomonas. Normal physiological changes predisposes the woman to a higher risk for pyelonephritis which can lead to complications like premature delivery, infants with low birth weight, IUGR, anaemia, thrombocytopenia, deranged liver function test and renal function test. Hence it is important to treat the infected group as $40 \%$ of asymptomatic bacteriuria develops symptomatic UTI. There is a good evidence of any type of urinary tract infection and sudden unexpected infant death. Relapse and reinfections are also common in pregnancy. Relapse is the occurrence of infection by the same strain of organism within six weeks of initial infection whereas reinfection is the recurrence of bacteria with a different strain of bacteria after successful eradication of initial infection. Approximately $15 \%$ of patients will have a recurrence during pregnancy necessitating repeat culture.

Screening for asymptomatic bacteriuria in pregnant women has been shown to be cost effective when compared with treating UTI and pyelonephritis without screening. The various screening techniques used to detect bacteriuria include urine analysis, leukocyte esterase activity, a nitrite test and urine cultures. A midstream urine culture is still considered the best diagnostic test. The American College of Obstetrics and Gynaecology advocates routine screening for bacteriuria with a urine culture at the first prenatal visit and during the third trimester.

\section{METHODS}

This was a cross sectional study done over a period of 12 months at this tertiary care centre in Government sector in Trivandrum, Kerala. A sample size was calculated statistically and 400 women with gestational age less than 28 weeks attending the outpatient department were included in this study. A structured proforma, urine microscopy and urine culture and sensitivity were the study tools.

$n=\frac{4 p q}{L^{2}}$

Where,

$\mathrm{p}=0.5$ (prevalence of disease)

$\mathrm{q}=(1-\mathrm{p})$ and
$\mathrm{L}=10 \%$ of $\mathrm{p}$

\section{Inclusion criteria}

- Age ranging between 20-40 years,

- Any parity

- Gestational age <28 weeks

- Singleton pregnancy,

- No history of rupture of membranes

- No history of preterm labour in previous pregnancies

\section{Exclusion criteria}

- Fever

- Symptoms of urinary tract infections such as hesitancy, dysuria, urgency, frequent voiding, incomplete voiding and incontinence

- Hypertension, diabetes

- Sickle cell disease

- History of antibiotic therapy in previous 2 weeks

- Known congenital anomalies of urinary tract

\section{Study procedure}

After informed consent, patient's personal and demographic details were obtained .Patient was instructed to collect mid steam clean catch urine sample in a sterile bottle. They were immediately transported to the laboratory and were processed within one hour. In case of delay it was refrigerated at 4 degree Celsius. Microscopy examination for pus cells in un-spun urine was examined directly under the microscope and pus cells per high power field were calculated. A count of 10 or more per high power field is an indication of urinary tract infection.

\section{Quantitative bacteriology}

The urine was cultured on blood agar, Mac conkey agar and CLED agar. A loopful of well mixed uncentrifuged urine was streaked on to the surface of culture plates. Incubation was done aerobically at $35 \mathrm{deg} \mathrm{C}$ for $18-24$ hours. A minimum of 24 hours was necessary to detect uropathogenic organisms. Pure growth of $\geq 1 \times 10^{5} \mathrm{CFU} / \mathrm{ml}$ of one organism was considered to be suggestive of significant bacteriuria. Mixed growth of 2 or more organism was considered as contamination. Significant bacterial isolates were identified by standard procedures and were subjected to antibiotic susceptibility by Kirby Bauer's disc diffusion method.

\section{RESULTS}

\section{Age distribution}

$46 \%$ women in this study were between the age group of 20-25 years, $36.5 \%$ were between $25-30$ years, $10.75 \%$ were above 30 years. Only $6.75 \%$ were less than 20 years of age. 


\section{Socioeconomic status}

$96.5 \%$ of study sample belonged to low socioeconomic group.

Table 1: Urine microscopy.

\begin{tabular}{|lll|}
\hline Microscopy & Number & Percentage \\
\hline Positive & 110 & 27.5 \\
\hline Negative & 290 & 72.5 \\
\hline Total & 400 & 100 \\
\hline
\end{tabular}

\section{Parity}

$82.45 \%$ were multigravidas and $15.75 \%$ were primigravida.

Table 2: Proportion of culture positives.

\begin{tabular}{|lll|}
\hline Asymptomatic bacteriuria & Number & Percentage \\
\hline Culture positive & 33 & 8.25 \\
\hline Culture negative & 367 & 91.75 \\
\hline Total & 400 & 100 \\
\hline
\end{tabular}

\section{Place of residence}

$82.25 \%$ belonged to rural areas.

\section{Educational status}

$44.5 \%$ women went up to high school.34.75\% had higher secondary education and $20.75 \%$ had pre-degree and higher education.

Table 3: Preterm labour.

\begin{tabular}{|lll|}
\hline & Yes & No \\
\hline Culture positive & $6(18.2 \%)$ & $27(81.8 \%)$ \\
\hline Culture Negative & $26(7.1 \%)$ & $341(92.9 \%)$ \\
\hline Chi-square =5.066 & P value-0.024 & \\
\hline OR-2.915 & 95\% CI-1.104-7.691 \\
\hline
\end{tabular}

Table 4: Symptomatic UTI.

\begin{tabular}{|lll|}
\hline UTI & $\begin{array}{l}\text { Culture } \\
\text { positive }\end{array}$ & Culture negative \\
\hline Present & $9(27.3 \%)$ & $28(7.6 \%)$ \\
\hline Absent & $24(72.7 \%)$ & $339(92.4 \%)$ \\
\hline Chi-square-13.917 & df-1 $\mathrm{p}<0.001$ \\
& Highly significant \\
\hline
\end{tabular}

\section{Urine microscopy}

In this study 110 out of 400 women (27.5\%) were microscopically positive for asymptomatic bacteriuria and 270(72.5\%) were negative (Table 1).
Table 5: Classification of fetal morbidity.

\begin{tabular}{|lll|}
\hline $\begin{array}{l}\text { Culture } \\
\text { positive }\end{array}$ & $\begin{array}{l}\text { Culture } \\
\text { negative }\end{array}$ \\
\hline Preterm & $5(15.2 \%)$ & $6(1.6 \%)$ \\
\hline Low Apgar score & 0 & $26(7.1 \%)$ \\
\hline LBW+preterm & $5(15.2 \%)$ & $6(1.6 \%)$ \\
\hline IUGR & $2(6.1 \%)$ & $6(1.6 \%)$ \\
\hline & $\begin{array}{l}\text { Chi-square- } \\
\text { 5.378 }\end{array}$ & df-1 p=0.020 \\
\hline & OR=3.03 & $95 \%$ CI-1.273- \\
& 7.238 \\
\hline
\end{tabular}

Table 6: Previous history of UTI.

\begin{tabular}{|lll|}
\hline $\begin{array}{l}\text { H/o of } \\
\text { UTI }\end{array}$ & $\begin{array}{l}\text { Culture } \\
\text { positive }\end{array}$ & Culture negative \\
\hline Present & $5(15.2 \%)$ & $19(5.2 \%)$ \\
\hline Absent & $28(84.8 \%)$ & $348(94.8 \%)$ \\
\hline Chi-square-5.341 & df-1 p=0.021 \\
\hline OR=3.271 & $95 \%$ CI-1.136-9.419 \\
\hline
\end{tabular}

\section{Proportion of culture positives}

Out of 400 women screened 110 were microscopically positive, and amongst them $33(8.25 \%)$ were culture positives. 367 women were culture negative. Thus the incidence of asymptomatic bacteriuria in the screened women was $8.25 \%$ (Table 2).

\section{Preterm labour}

$18.2 \%$ had preterm labour in culture positive cases whereas $7.1 \%$ in culture negative cases had preterm labour. So preterm labour has significant correlation with asymptomatic bacteriuria (P value 0.024) (Table 3).

\section{Gestational hypertension}

There were only 3 cases of gestational hypertension in culture positive cases whereas 21 in culture negative cases which were statistically insignificant.

\section{Presence of preeclampsia}

2 cases of preeclampsia was noted out of 33 culture positive cases compared to 2 in culture negative cases which was statistically significant.

\section{Acute pyelonephritis}

There was a single case of pyelonephritis in culture positive case and no case of pyelonephritis was there in culture negative cases which were statistically insignificant. 


\section{Maternal anaemia}

There were 2 cases of maternal anaemia in culture positive cases compared to 19 cases in culture negative cases which was also insignificant statistically.

\section{Symptomatic UTI}

There were 9 cases of symptomatic UTI in culture positive cases which accounts for $27.3 \%$ compared to 28 cases in culture negative cases(7.6\%) which was highly statistically significant(p value<0.001) (Table 4).

\section{Foetal morbidity}

Foetal morbidity as defined by prematurity ( $<37$ weeks), birth weight $<2.5 \mathrm{~kg}$, Apgar score $<7 / 10$ and IUGR were compared amongst culture positives and negatives. Low birth weight showed a statistically significant correlation but the rest did not show a statistically significant correlation in this study. Prematurity was however the most common fetal morbidity $(18.2 \%)$ followed by low birth weight (15.2\%) and IUGR (6.1\%). $76 \%$ of culture positive cases and $90.5 \%$ of culture negative cases did not have any fetal morbidity. This was statistically significant (Table 5).

\section{Previous history of UTI}

$15.2 \%$ of antenatal women who were culture positive cases had previous history of UTI compared to $5.2 \%$ in culture negative cases without asymptomatic bacteriuria which was statistically very significant (Table 6)

\section{Mode of delivery}

Around $84.8 \%$ of culture positive cases had a vaginal delivery and $15.2 \%$ had CS. In the culture negative group $75.5 \%$ had vaginal delivery and $24.5 \%$ had a CS which was not statistically significant.

\section{Commonest pathogen}

E coli were isolated in $57.6 \%$ cases followed by Klebsiella in $27.3 \%$ cases and $15.3 \%$ had coagulase negative staphylococci.29 cases had sensitivity to nitrofurantoin and 4 cases did not.

\section{ICU admissions}

One baby in culture positive cases and 14 in culture negative cases were admitted to ICU which was not significant.

\section{DISCUSSION}

In the present study the prevalence of asymptomatic bacteriuria was $8.25 \%$. Different studies have shown varying incidences from $2-30 \%$ depending on the group under study like gestational diabetes. In this study gestational diabetes was excluded. The dominant isolates in the study was E.coli which accounted to about $57.6 \%$, others were Klebsiella, and coagulase negative staphylococcus which were found in less numbers. This is similar to the findings of previous studies by Kass et al, Fatma $\mathrm{N}$ et al, Isabel $\mathrm{N}$ et al, Jayalakshmi et al. ${ }^{3-6}$

The highest age specific prevalence in the current study was found in age group of 20-25 and lowest in $<20$. This is probably because majority of patients that reported to our institution belonged to this age group. Mean age of 25 yrs was also noted by Selassie G. ${ }^{7} 82.45 \%$ of study population in the present study were multigravida. Several authors have reported increasing rise of asymptomatic bacteriuria with age and parity like Patrick $\mathrm{M}$ et al in their study. Most $(96.5 \%)$ of the patients in the present study belonged to low socioeconomic group as is true with most of the other studies e.g. Whalley et al. ${ }^{8}$ However, Gulfareen et $\mathrm{al}^{9}$ did not find any association of socio economic status with bacteriuria. Preterm births in the current study were $18.2 \%$ in asymptomatic bacteriuria patients. Meta-analysis of exposure to antenatal UTI has a relative risk of 1.5 and 2 for association with low birth and prematurity respectively. This was confirmed by Robert Mittendorf et $\mathrm{al}^{10}$ by a Meta-analysis Low birth weight was seen in $15.2 \%$ of the present study. Romero et al ${ }^{11}$ proved that there was strong association between untreated urinary tract infection and low birth weight. Incidence of gestational HTN and preeclampsia were $9.1 \%$ and $6.1 \%$ respectively in this study. Abayad et $\mathrm{al}^{12}$ found that asymptomatic bacteriuria was associated with hypertension and preeclampsia. In his study $10 \%$ of women with bacteriuria and $8.9 \%$ women without bacteriuria developed gestational hypertension. However there is no compelling evidence of an association of asymptomatic bacteriuria with hypertension in pregnancy or of long term renal damage associated with asymptomatic bacteriuria of pregnancy in the antibiotic era. ${ }^{13}$ The pregnant women who had previous history of UTI were approximately three times more likely to develop asymptomatic bacteriuria compared to those who had no history of UTI, in this study. Various studies ${ }^{14,15}$ showed that the history of UTI is considered as strongest predictor of asymptomatic bacteriuria. The study found that nitrofurantoin is effective for most of the isolates in the study $(87.9 \%)$. The prevalence of resistance by urinary isolates to nitrofurantoin and gentamicin was $0 \%-2 \%$ as proved by Gupta et $\mathrm{al}^{16}$. He stated that nitrofurantoin is relatively safe in pregnancy and is effective in most UTI, except that it can cause haemolysis in a glucose 6 phosphate deficiency baby, if used near term. So, first trimester urine culture remains the screening test of choice as advocated by Nicotle et $\mathrm{al}^{17}$ and American academy of family physician ${ }^{18}$ and several others. The ideal time for it to be done was considered to between 12-16 weeks of gestation. 


\section{CONCLUSION}

In our study, out of 400 antenatal women, 33 were found to have asymptomatic bacteriuria, which gives a prevalence rate of $8.25 \%$. E coli was found to be the most common organism accounting for $57.5 \%$ in our study. Other organisms isolated were Klebsiella and coagulase negative staphylococci. We found that pregnant women with asymptomatic bacteriuria were at an increased risk for several adverse maternal and fetal outcomes. Out of maternal morbidity, gestational hypertension and preeclampsia were $9.1 \%$ and $6.1 \%$ in patients with asymptomatic bacteriuria compared to patients without asymptomatic bacteriuria where it was $5.7 \%$ and $0.5 \%$ respectively. The fetal risks were prematurity $(18.2 \%)$ and low birth weight $(15.2 \%)$ in patients with asymptomatic bacteriuria compared to $7.1 \%$ and $1.6 \%$ in patients without asymptomatic bacteriuria. Hence pregnant women should be screened for bacteriuria and treated if test results are positive. It is recommended that all antenatal women should be screened for asymptomatic bacteriuria at an early pregnancy preferably less than 28 weeks of gestation. More studies with a larger sample size will help to reinforce the findings of previous studies.

\section{ACKNOWLEDGEMENTS}

We would like to express our heartfelt gratitude to Dr. Nirmala C, Professor and HOD, Department of Obstetrics and Gynaecology, Medical College Trivandrum for her guidance and support in this research work. We also extend our sincere thanks to Dr. Jacob George, Head of Department of Nephrology for his assistance during this study. We also thank Dr. Babu and Shri Jayakumar for helping us in carrying out the statistical analysis.

Funding: No funding sources

Conflict of interest: None declared

Ethical approval: The study was approved by the Institutional Ethics Committee

\section{REFERENCES}

1. Lavanya SV, Jogalakshmi D Asymptomatic bacteriuria in antenatal women. Indian $\mathrm{J}$ Med Micribiol. 2002;20:105-6.

2. DeIzell JE, Lefevre ML. Urinary tract infections during pregnancy. Am Fam Physician. 2000;61(3):713-21.
3. Kass EH. Asymtomatic infections in urinary tract. Trans Assoc Am Physicians. 1956;69:56-64.

4. Fathima N, Yasmin S, Ishrat S. Prevalence and complications of asymtomatic bacteriuria during pregnancy: Professional Med J. 2006;13(1):108-12.

5. Nerissa Isabel C, Carla Elena J. Prevalence of Asymptomatic Bacteriuria and Associated Risk Factors in Pregnant Women. Phil J Microbiol Infect Dis. 2003;32(2):63-9.

6. Jayalaxmi J, Jayaram VS. Evaluation of various screening tests to detect asymptomatic bacteriuria in pregnant women: IJPM. 2008;51(3):379-81.

7. Selassie S. Asymptomatic bacteriuria in pregnancy: epidemiological, clinical and microbiological approach. Ehiop Med J. 1998;36(3):185-92.

8. Whalley P. Bacteriuria of pregnancy. Am J Obstet Gynecol. 1967;97:723-38.

9. Haider G. Risk factors of urinary tract infection in pregnancy. J Pak Med Assoc. 2010;62(3):213-6.

10. Mittendorf R. Prevention of preterm delivery and low birth weight associated with asymtomatic bacteriuria. Clin Infec Dis. 1992;14(4):927-32.

11. Romero R, Oyarzane E. Meta analysis of relationship between asymtomatic bacteriuria and preterm delivery/low birth weight. Obstetrics and Gynaecology. 1989;73:576-82.

12. Abyad A. Screening for asymptomatic bacteriuria in pregnancy urinalysis versus urine culture. J Fam Pract. 1991;33(5):471-4.

13. Patterson TF, Andriole VT. Bacteriuria in pregnancy. Infect Disclin North Arm 1987;1:807-22.

14. Macejko AM, Schaeffer AJ. Asymptomatic bacteriuria and symptomatic UTI in pregnancy. Urol Clin North Am. 2007;34(1):35-42.

15. Hazhir S. ABU in pregnant women Uro J. 2007;4(1):24-7.

16. Gupta K, Hillier SL, Hooton TM, Roberts PL, Stamm WE. Effects of contraceptive method on the vaginal microbial flora: a prospective evaluation. J Infect Dis. 2000;181:595-601.

17. Towers CV, Kaminskas CM, Garite TJ. Pulmonary injury associated with antepartum pyelonephritis: can patients at risk be identified? Am J Obstet Gynecol. 1991;164:974-8.

18. American Academy of Family Physicians. Summary of recommendations for clinical preventive services. Revision 6.4. August 2007.

Cite this article as: Radha $\mathrm{S}$, Nambisan B, Prabhakaran NK, Jamal S. Prevalence and outcome of asymptomatic bacteriuria in early pregnancy. Int $\mathrm{J}$ Reprod Contracept Obstet Gynecol 2017;6:223-7. 